\title{
Integrated security levels and analysis of their implications to the maintenance
}

\author{
M. KORYTAR AND D. GABRISKA
}

\begin{abstract}
The article describes the main indicators of the functional safety systems, which are related to the safety of technological processes. There is also an evaluated example in accordance with the recommendations of the standards IEC61508 and IEC 61511. In this paper, we analyzed their dependence on the organization of maintenance and diagnosis of these systems.
\end{abstract}

General Terms: Functional Safety, Safety Integrity Level, Human Factors

Additional Key Words and Phrases: Process Safety Management, Risk Reduction Factor, Mean Time To Failure, Probability of Failure on Demand

\section{INTRODUCTION}

The management of functional safety is the most important part of the standards IEC 61508 and IEC 61511 [BS IEC 61511. 2003]. Applications of all companies, which include some of the steps of the life cycle, must handle the Process Safety Management (FSM) system. FSM system should specify the management and technical activities necessary to achieve the desired functional safety. We shall demonstrate satisfying life cycle, processes to be used, responsibilities and privileges of individuals, departments and organizations, available verification form and validity check, etc. It is necessary that all activities will be carried out by this process, so that they can be controlled. All decisions should be made in a way that they are clear and could be easily identified.

\section{SAFETY INTEGRITY LEVELS}

The intention of FSM is to prevent and avoid disruptions of the safety devices built into the system, and to avoid distortions in the operation and maintenance of technological equipment. Legislative standards focus on the management of all activities that are necessary to ensure the safe application design and operation of the 
equipment or its installation itself. Serious risks to the equipment and to any related management systems should be defined by the supplier or manufacturer by analyzing operational safety. The analysis determines whether the functional safety is required to ensure adequate protection of all significant risks. This should be properly taken into account when designing the system. Functional safety is just one of the methods for working with risks. There are also other methods to eliminate or reduce risks. For example, own safety is extremely important as a part of the design. Standard (IEC 61508) applies to safety-related systems, only if one or more of these systems includes electrical, electronic or programmable electronic device (E / E / PE). This standard relates to the potential danger caused by failure of safety functions performed by E / E / PE systems and is related to ensuring their safety. With regard to the security, the standard refers to the whole E / E / PE system (starting from the sensor, with the use of logic control devices and communication systems, to the final actuator, including all relevant actions taken by a human operator). The long-term health damage, including damage to the environment, which is harmful to health in the long term, clearly falls within the scope of this standard (IEC 61508-4) and is included in the safety concept.

Some of the required safety functions and corresponding performance levels are determined by the risk analysis and the operational safety (IEC 61508-5). The equivalent analysis of environmental risks and financial risks can be accomplished by setting the security in the field of the environment or financial parameters. Like any other part of the system, software safety integrity level does not exist in isolation from the safety-related system. The software, which is integrated into the system, can maintain the safety function at a certain level of security depending on its purpose, configuration, implementation and verification.

The standard IEC 61508 describes two operating modes associated with the functional safety. This is about a low demand mode and a high demand mode or a continuous mode of operation. These terms are formally defined in paragraph 5.3.12 of IEC 61508-4.

Before a security system starts, it must be proved by calculation that the supplied security system meets and complies with SIL. There are several methods for 
calculating the level of achieved integrity. The first parameter, which determines the level of integral safety SIL (Safety Integrity Level), is the average probability of failure $P F D_{\text {avg }}$ (Probability of Failure on Demand). The factor in reducing the risk of $R R F$ (Risk Reduction Factor), which is the ratio of the incidents without protective measures divided by permissible frequency of incidents, is the variable $P F D_{\text {avg }}, R R F$ $=1 / P F D_{\text {avg }}$. That means, that if the number of cases without a protective actions is 10 per year, and the acceptable number of cases is equal to 1 per 100 years, then RRF should be equal to 1000 , respectively $P F D A V G=0,001$ annually. This value is in accordance with the standard IEC 61508 and corresponds to the safety SIL 2.

Table1. Safety integrity levels: target failure measures for a safety function: Allocated to an E/ E/PE safety - related system operating in law demand mode of operation []

\begin{tabular}{|c|c|c|}
\hline $\begin{array}{c}\text { Safety } \\
\text { integrity } \\
\text { level } \\
\text { (SIL) }\end{array}$ & $\begin{array}{c}\text { Low demand mode of operation } \\
\text { Average probability of failure to perform } \\
\text { its design function on demand) }\end{array}$ & $\begin{array}{c}\text { High demand or continuous mode of } \\
\text { operation } \\
\text { (Probability of a dangerous failure per } \\
\text { hour) }\end{array}$ \\
\hline 4 & $\geq 10^{-5}<10^{-4}$ & $\geq 10^{-9}<10^{-8}$ \\
\hline 3 & $\geq 10^{-4}<10^{-3}$ & $\geq 10^{-8}<10^{-7}$ \\
\hline 2 & $\geq 10^{-3}<10^{-2}$ & $\geq 10^{-7}<10^{-6}$ \\
\hline 1 & $\geq 10^{-2}<10^{-1}$ & $\geq 10^{-5}<10^{-4}$ \\
\hline
\end{tabular}

Since the year has about 10,000 hours, security tools SIF (Safety Instrumented Function) are not available approximately 10 hours per year. During this time, the system is unable to provide controlled transfer of the technological process to a safe state. If this period is too long, the unavailability of SIF must be reduced for example, to 1 hour per year. Its integral security level should be higher, for example SIL3. Mean time between failures and the failure rate MTTF (Mean Time To Failure) is a measure of the average period of the successful operation of the equipment (system) to a failure of any kind. This information can be interpreted as the lifetime of the equipment if it cannot be restored or repaired.

The characteristic of repaired units is the average duration of their repair MTTR (Mean Time To Repair). The average time between two subsequent failures (Mean Time Between Failures) is usually expressed in years. The following ratio applies between these indicators $M T B F=M T T F+M T T R$. MTBF value is very important 
because its reciprocal $\lambda=1 / M T B F$ is the intensity of the failure of the device. The overall failure rate $\lambda_{\text {tot }}$ is divided into two basic categories:

- The intensity of safe failures $\lambda_{\mathrm{s}}$

- The intensity of unsafe failures $\lambda_{d}$

$$
\lambda_{\text {tot }}=\lambda_{\mathrm{s}}+\lambda_{\mathrm{d}}
$$

The risk of the failure, leads to a loss of functionality of the security system or to a loss of a safe state. During a failure state the system can be considered as safe, when it leads to the incorrect output stop and to the break of the technological process (false tripping) with regard to the systems which are normally in the "on" state (eg. Safety systems). Dangerous failures are those, which prevent disconnection of the output and stop the process in case of emergency. Each category is further divided into detectable $\left(\lambda_{\mathrm{sd}}, \lambda_{\mathrm{dd}}\right)$ and undetectable $\left(\lambda_{\mathrm{su},} \lambda_{\mathrm{du}}\right)$ on-line diagnostics.

$$
\begin{gathered}
\lambda_{\mathrm{s}}=\lambda_{\mathrm{sd}}+\lambda_{\mathrm{su}} \\
\lambda_{\mathrm{d}}=\lambda_{\mathrm{dd}}+\lambda_{\mathrm{du}} \\
\lambda_{\mathrm{tot}}=\lambda_{\mathrm{sd}}+\lambda_{\mathrm{su}}+\lambda_{\mathrm{dd}}+\lambda_{\mathrm{du}}
\end{gathered}
$$

The reverse value $\lambda_{\mathrm{s}}$ is $M T B F_{\mathrm{s}}$, or the average time (in years) between the possible false stops. On the other side, the reverse value $\lambda_{\mathrm{d}}-M T B F_{\mathrm{d}}$ is the average time (in years) between potentially dangerous disorders.

\section{DETERMINATION OF THE DIFFERENT CATEGORIES OF A FAILURE}

Determination of the different categories of a failure is generally carried out at the design stage of specific equipment (e.g. Fig. 1a). For this purpose, the diagnostics of the fault types are analyzed (Failure Mode Effect and Diagnostic Analysis - FMEDA). The diagram in the Fig. $1 \mathrm{~b}$ is used to explain the principle of FMEDA. The Fig. 1b shows a diagram of possible temperature sensor states of heating winding dryers with current output.

Sensor - temperature converter with the current output $4 \ldots 20 \mathrm{~mA}$ is tested for the determination of $\lambda_{\mathrm{sd}}, \lambda_{\mathrm{su}}, \lambda_{\mathrm{dd}}, \lambda_{\mathrm{du}}$. We are using the estimation, that the transmission range variation of the temperature measurement is $0.8 \mathrm{~mA}$ ( $5 \%$ of operation margin). 
Therefore, the sensor supply output is set to $12 \mathrm{~mA}$. Then we gradually model different kinds of faults (short circuit, open circuit, deviation, etc.) for each component of the sensor.

For example, if the resistor is $1 \mathrm{k}$, its value is gradually set to $0,500,2000 \Omega$ and then it is disconnected. The output changes are recorded. If the range of the changes is less than $0.8 \mathrm{~mA}$, the failure is classified as safe undetectable $(s u)$. If the signal is out of the tolerance range, but is in the range $4 \ldots 20 \mathrm{~mA}$, the failure is classified as dangerous undetectable $(d u)$. If the signal has exceeded the permitted deviation, but is in the range from $4 \mathrm{~mA}$ or over $20 \mathrm{~mA}$, the failure can be safe or dangerous depending on the conditions of the application. In any case, it will be classified as detectable. Such testing and analysis is performed for each component. To evaluate the common values of failure intensity $\lambda_{\mathrm{sd}}, \lambda_{\mathrm{su}}, \lambda_{\mathrm{dd}}, \lambda_{\mathrm{du}}$. the measured results will be summed. It should be noted that the determination of unavailability of safety system $\left(P F D_{\text {avg }}\right)$ has the general intensity value of undetectable dangerous failures $(d u)$. This means that the lower the value, the higher the SIL integral security level can be achieved for the device. The proportion of the safe failures SFF (Safety Failure Fraction) is the second parameter which is defining the integral security level. According to the IEC61508 standard, the components and subsystems are type A or type B (see table 2 and table 3 ): 
- Type A components - simple devices with known behavior and failure modes

- Type B components - complex parts with potentially unknown failure types such as microprocessors, specialized processors, etc.
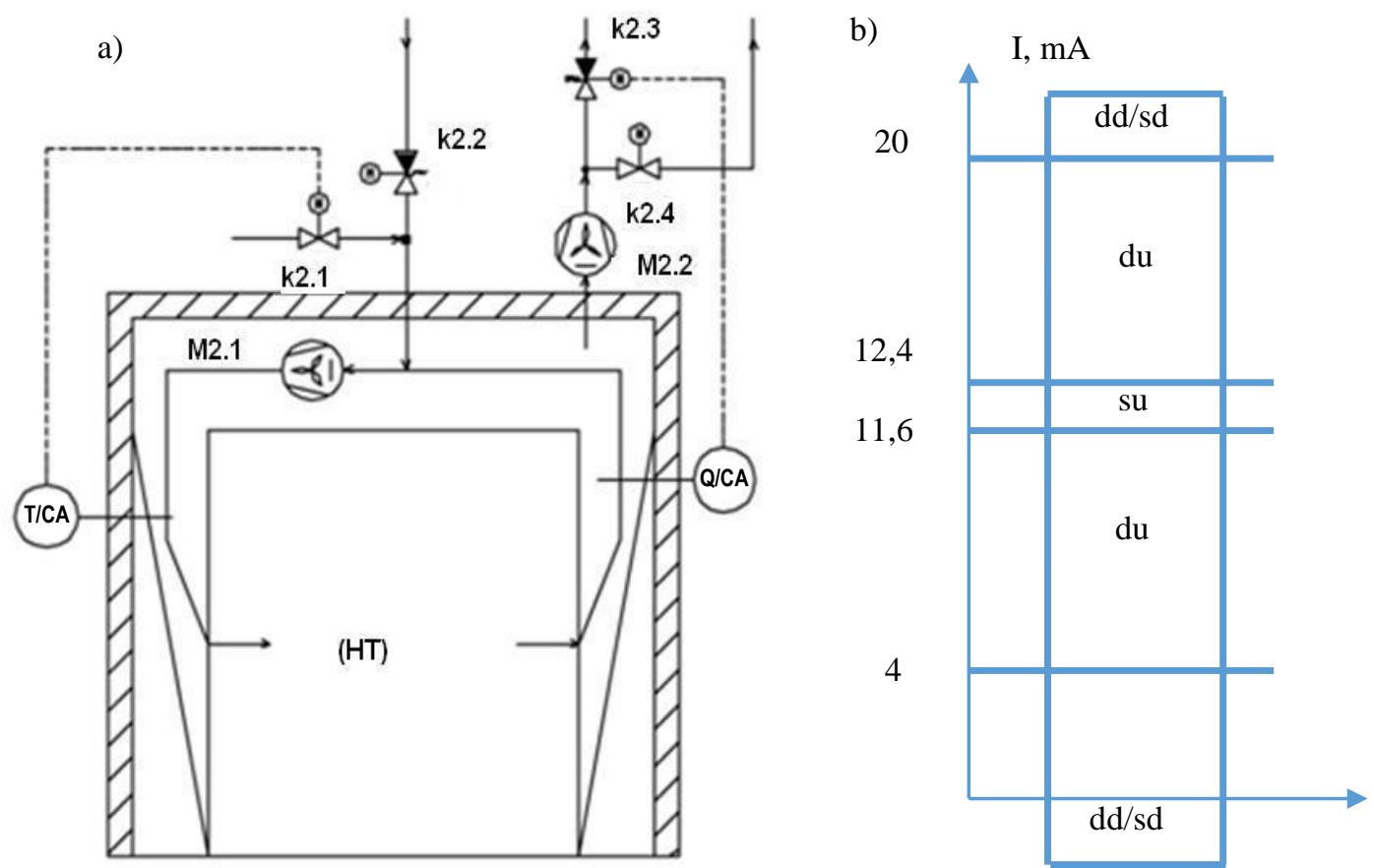

Fig.1 a) Heating of the winding dryers b) analysis of failure modes and diagnostics

Table 2 and table 3 shows the limits for using simple redundant architectures for systems with different $S I L$ levels. $S F F$ value is determined according to the figure [CHRIS, J. 2003]:

$$
S F F=\frac{\sum \lambda_{\mathrm{dd}}+\sum \lambda_{\mathrm{sd}}+\sum \lambda_{\mathrm{su}}}{\sum \lambda_{\mathrm{dd}}+\sum \lambda_{\mathrm{du}}+\sum \lambda_{\mathrm{sd}}+\sum \lambda_{\mathrm{su}}}=1-\frac{\sum \lambda_{\mathrm{du}}}{\sum \lambda_{\mathrm{dd}}+\sum \lambda_{\mathrm{du}}+\sum \lambda_{\mathrm{sd}}+\sum \lambda_{\mathrm{su}}}
$$


Table2: Safe failure fraction $(S F F)$. Law demand mode of operation (Type A)

\begin{tabular}{|c|c|c|c|}
\hline SFF & $\begin{array}{c}\text { Immunity to } \\
\text { hardware failures 0 }\end{array}$ & $\begin{array}{c}\text { Immunity to } \\
\text { hardware failures } \\
1\end{array}$ & $\begin{array}{c}\text { Immunity to } \\
\text { hardware failures } 2\end{array}$ \\
\hline$<60 \%$ & SIL 1 & SIL 2 & SIL 3 \\
\hline $60-90 \%$ & SIL 2 & SIL 3 & SIL 4 \\
\hline $90-99 \%$ & SIL 3 & SIL 4 & SIL 4 \\
\hline$>99 \%$ & SIL 3 & SIL 4 & SIL 4 \\
\hline
\end{tabular}

Table3: Safe failure fraction. High demand or continuous mode of operation (Type B)

\begin{tabular}{|c|c|c|c|}
\hline \multirow{2}{*}{ SFF } & $\begin{array}{c}\text { Immunity to } \\
\text { hardware failures } 0\end{array}$ & $\begin{array}{c}\text { Immunity to } \\
\text { hardware failures 1 }\end{array}$ & $\begin{array}{c}\text { Immunity to } \\
\text { hardware failures } 2\end{array}$ \\
\hline$<60 \%$ & Not allowed & SIL 1 & SIL 2 \\
\hline $60-90 \%$ & SIL 1 & SIL 2 & SIL 3 \\
\hline $90-99 \%$ & SIL 2 & SIL 3 & SIL 4 \\
\hline$>99 \%$ & SIL 3 & SIL 4 & SIL 4 \\
\hline
\end{tabular}

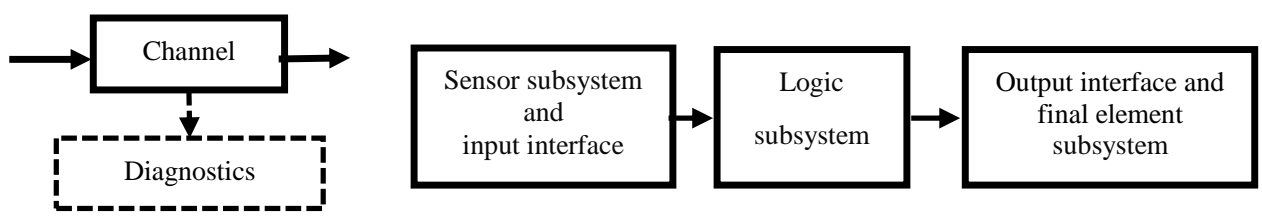

Fig.2. 1001 physical block diagram (IEC 61508-6)

If we would like to increase $S F F$, the total value $\sum \lambda_{\mathrm{du}}$ should be as small as possible. To calculate $P F D_{\text {avg }}$ of architecture of 1001 systems (fig.2) applies [LEVESON, N. A. 2004]:

$$
P F D_{\mathrm{avg}}(T i)=\lambda_{\mathrm{dd}} R T+\lambda_{\mathrm{du}} T i / 2
$$

Where $R T$ is the time of recovery in hours (usually 8 hours), TI is the time interval between the functional screening tests in hours $(1-5-10$ years, 1 year $=8.760$ hours) and is labeled as $T_{\text {proof }} \lambda_{\mathrm{dd}}$ is the intensity of detectable dangerous failures. $\lambda_{\mathrm{du}}$ is the intensity undetectable dangerous failures. For $T_{\mathrm{i}}=1$ year $=8760 \mathrm{~h}$ and $R T=8 \mathrm{~h}:$

$$
P F D_{\mathrm{avg}}=8 \lambda_{\mathrm{dd}}+\frac{8760 \lambda_{\mathrm{du}}}{2} \approx 4380 \lambda_{\mathrm{du}}
$$


Figure 3 shows the $P F D$ and $P F D_{\text {avg }}$ of 1001 system architecture and the interval $T P_{\text {roof }}$, which is equal to 1 year. Where $P F D$ is the probability of the implementation of the failed queries to perform safety functions except of the diagnostics tests to detect the undetectable faults. $P F D_{\text {avg }}$ is the average probability of failing of the safety functions queries, with regard to the implementation of the diagnostic tests. There are special procedures for diagnostic tests to detect the intensity of dangerous undetectable failures $\sum \lambda_{\mathrm{du}}$ for each unit, which are detectable by conventional diagnostic on-line tests. If we do not want to perform regular tests, then the value $P F D$ of the safety functions $S I F$ will be moved from current level to a lower level.

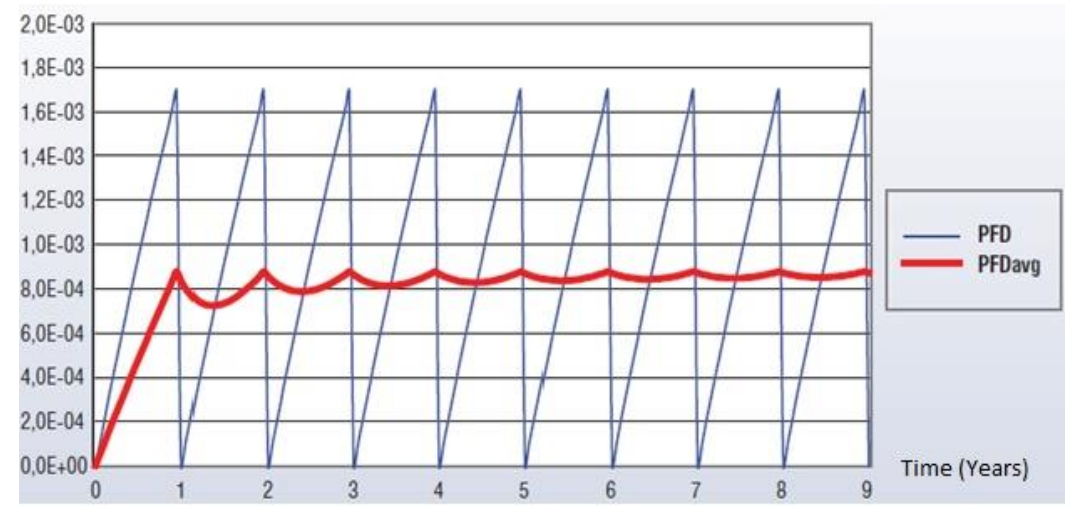

Fig. 3: 1oo1 · physical block diagram (IEC 61508-6)

Table4. Factor in reducing the risk as a function of the level SIL and Ready

\begin{tabular}{|c|c|c|c|c|}
\hline $\begin{array}{c}\text { SIL } \\
\text { Safety } \\
\text { Integrity } \\
\text { Level }\end{array}$ & $\begin{array}{c}\text { PFD }_{\text {avg }} \\
\text { Lawand mode of } \\
\text { operation } \\
\text { (Type A) }\end{array}$ & $\begin{array}{c}\text { 1-PFD } \\
\text { Safety } \\
\text { ready }\end{array}$ & $\begin{array}{c}\text { RRF } \\
\text { Risk Reduction } \\
\text { Factor }\end{array}$ & $\begin{array}{c}\text { PFD }_{\text {avg }} \\
\text { High demand or } \\
\text { continuous mode of } \\
\text { operation (Type B) }\end{array}$ \\
\hline SIL 4 & $\geq 10^{-5} \leq 10^{-4}$ & $99.99-99.999 \%$ & $100000-10000$ & $\geq 10^{-9} \leq 10^{-8}$ \\
\hline SIL 3 & $\geq 10^{-4} \leq 10^{-3}$ & $99.9-99.99 \%$ & $10000-1000$ & $\geq 10^{-8} \leq 10^{-7}$ \\
\hline SIL 2 & $\geq 10^{-3} \leq 10^{-2}$ & $99-99.9 \%$ & $1000-100$ & $\geq 10^{-7} \leq 10^{-6}$ \\
\hline SIL 1 & $\geq 10^{-2} \leq 10^{-1}$ & $90-99 \%$ & $100-10$ & $\geq 10^{-6} \leq 10^{-5}$ \\
\hline
\end{tabular}

Table 4 shows the $P F D_{\text {avg }}$ values in 2 modes [SMITH, D. J., 2001]: 
- Mode with low query intensity: in this mode the frequency of the safety function queries is not more than one query per year and not more than double frequency of screening tests.

- Mode with high query intensity: in this mode the frequency of safety function queries is not more than one query per year and more than double frequency of screening tests.

The amount of screening tests shows the frequency of performing functional tests of the safety systems, so it is possible to guarantee their functionality. For the mode with low query intensity, the given values correspond to the time interval of one year. Because one year has approximately 10000 hours, the $P F G_{\text {avg }}$ values in both modes are approximately the same.

\section{CONCLUSION}

It should be noted that the decrease of the risk factor $R R F$ is the reverse value of $P F G_{\text {avg. }}$. To assess SIL levels, it is easier to use $R R F$ factor, because the positive integers are more intuitive. When assessing the SIL levels, we should note:

- $\quad$ The values from the table 4 applies to the safety functions of SIF as a whole and not to its parts

- The difference between two SIL levels is 10. The same difference of one order (10) exists between the minimal and maximal values for each SIL level. For example, $R R F=120$ SIL2 and $R R F=980$ also applies to SIL2, but there is a big difference between them. These two values cannot be compared, even though both apply to the SIL2.

- There is one misunderstanding that the SIL levels $(1-2-3-4)$, which are defined to instrumental function of safety system, are the same. This is however not correct, because the safety SIL levels depend on the probability $P F D$, which increases over time. SIL level remains constant only for certain period of time $T P_{\text {roof }} T P_{\text {roof }}$ is a time interval between screening tests of the system security. The interval is usually $1,3,5,10,15$ years ( $T i$ parameter). 
- SIL level, which corresponds to the 1 year test interval is significantly different from the level which corresponds to the 10 year test interval, even though both belongs to the same safety function.

- $\quad$ There are two ways to improve SIL quality of specific SIF: lowering the test interval $T P_{\text {roof }}$ and using the redundant components, or combination of both methods

\section{REFERENCES}

BS IEC 61511. 2003. Functional safety - Safety instrumented systems for the process industry sector.

CHRIS, J. 2003. A Handbook of Incident and Accident Reporting. Glasgow University Press. ISBN 0-85261-784-4.

LEVESON, N. A. 2004. New Accident Model for Engineering Safer Systems. Safety Science, Vol. 42, No. 4, April 2004, 237-270.

SMITH, D. J., 2001. Reliability, Maintainability and Risk, 6th Edition, ISBN 0-7506-5168-7

SMITH, D. J., AND KENNETH GL SIMPSON. 2011. Safety Critical Systems Handbook. Third Edition. ISBN: 978-0-08-096781-3.

Received November 2014

Marek Korytar, Institute of Applied Informatics, Automation and Mathematics, The Faculty of Materials Science and Technology (MTF STU) in Trnava, Slovakia 91724;

Darja Gabriska,

Department of Applied Informatics,

The University of Ss. Cyril and Methodius, Slovakia 91701; 